\title{
Availability of Adequately lodized Salt at Household Level and Its Associated Factors in Horro Woreda, Horro Guduru Wollega Zone, Oromia, Ethiopia
}

\author{
Tamiru Yazew \\ Department of Food Science and Nutrition, College of Agriculture, Wollega University, Shambu, Ethiopia
}

Email address:

tamiruyazew2012@gmail.com

\section{To cite this article:}

Tamiru Yazew. Availability of Adequately Iodized Salt at Household Level and Its Associated Factors in Horro Woreda, Horro Guduru Wollega Zone, Oromia, Ethiopia. Pathology and Laboratory Medicine. Vol. 4, No. 1, 2020, pp. 20-26. doi: 10.11648/j.plm.20200401.14

Received: November 22, 2019; Accepted: April 16, 2020; Published: April 30, 2020

\begin{abstract}
Iodine Deficiency Disorder (IDD) is one of the biggest worldwide public health problems of today. Even if the coverage of iodized salt in Ethiopia is irregularly increasing, the coverage of households that use adequately iodized salt in different rural communities of Ethiopia was low. A community based cross sectional study was designed to assess availability of adequately iodized salt at household level and its associated factors in Horro woreda, Oromia regional state, Ethiopia from February to March, 2018. Data was collected using a structured and pretested questionnaire. Multistage sampling technique was used to select households and data were analyzed using SPSS v. 20. Variables having p $<0.25$ in the bivariate logistic regression were entered into multivariate logistic regression analysis and finally, variables having $\mathrm{p}<0.05$ and $95 \%$ confidence internal (CI) were considered as significantly associated. The finding of this study revealed that about $23.6 \%$ respondents were utilized adequately iodized. The study also found that the knowledge and practice among participants was $63.8 \%$ and $60 \%$, respectively. Moreover, access to information AOR $(95 \% \mathrm{CI})=2.5(1.1-5.55)$, wealth status AOR $(95 \% \mathrm{CI})=4.7(2.5-8.83)$, knowledge about the benefits of iodized salt AOR $(95 \% \mathrm{CI})=1.4(1.6-2.08)$ and salt storage place AOR $(95 \% \mathrm{CI})=4.2(2.33-$ 13.54) were significantly associated with availability of adequately iodized salt during multivariate analysis. This study concluded that the proportion of households covered by adequately iodized salt in rural communities of the study was very low (23.6\%) compared to the internationally recommended value to control iodine deficiency disorder (90\%). Therefore, nutrition interventions through behavioral change communication (BCC) towards adequately iodized salt utilization and its practice should be strengthen by all concerned bodies to increase its coverage and to eliminate iodine deficiency disorders in rural communities of the study area.
\end{abstract}

Keywords: Adequately Iodized Salt, Availability, Associated Factors, Horro Woreda

\section{Background}

Iodine is an essential micronutrient for humans required in a very small amount [8]. The daily recommended amount of iodine for normal function of thyroid gland is $150-200 \mu \mathrm{g} / \mathrm{l}$ for adults, $90-120 \mu \mathrm{g} / 1$ for children and $250 \mu \mathrm{g} / 1$ for pregnant and lactating mothers [19]. World health organization recommends (WHO) that the median iodine urinary level need to be within the range (100-199 $\mu \mathrm{g} / \mathrm{l})$ to ensure adequate iodine content in salt and other sources of iodine in the diet. However, when iodine intake falls below the recommended levels, the thyroid may no longer be able to synthesize sufficient amounts of thyroid hormones. This low level of thyroid hormones in the body is responsible for iodine deficiency disorders (IDD).

The human body does not make iodine, so it is an essential part of diet [5]; found in various foods such as cheese, cow's milk, eggs, frozen yogurt, ice cream, Iodine containing multi vitamins, iodized table salt, saltwater fish seaweeds, shellfish, soymilk and soy sauce.

Failure to have adequate iodine leads to insufficient production of thyroid hormones, which affect many different parts of the body, particularly muscle, heart, liver, kidney, thyroid gland, and the developing brain [22]. Inadequate hormone production adversely affects these tissues resulting in the disease collectively known as IDD. Long term 
deficiency in iodine intake is associated with the development of goiter. Iodine deficiency continues to be a significant public health problem in many developing countries [19]. Its deficiency not only causes goiter, it may also result in abortion, mental and growth retardation, irreversible brain damage and retarded psychomotor development in the fetus, infant and child [16].

Iodine Deficiency Disorder (IDD) is one of the biggest worldwide public health problems of today. In Ethiopia, among the four countries included in the review, the highest iodine deficiency $(86 \%)$ and high goiter prevalence $(14 \%$ to $59 \%$ ) was reported [23]. Iodization of salt is first line measure to prevent and control IDD. That was the reason why the Ethiopian Council of Ministers passed salt legislation in February 2011; according to this regulation, every salt for human consumption need to be iodized, and any iodized salt for human consumption shall conform to the standards for iodized salt set by the appropriate authority [12]. However, in Ethiopia about $47.5 \%$ of school children had urinary iodine levels less than $100 \mu \mathrm{g} / \mathrm{L}$ and about $51.8 \%$ of women had urinary iodine levels less than $100 \mu \mathrm{g} / \mathrm{L}$ and only $23.2 \%$ of urban and $13.3 \%$ of rural households were reported to have used iodized salt [10].

Another survey done by Ethiopian Public Health Institute (EPHI) also showed that only $26 \%$ of the total households were getting $>15 \mathrm{ppm}$ iodine in salt and about 66 million persons were unprotected from IDD and only $15 \%$ of households had access to iodized salt [13]. To ensure adequate availability and use of iodized salt, the government of Ethiopia has set a goal to virtually eliminate IDD by the year 2015 through universal salt iodization by increasing the proportion of households using iodized salt from $15.4 \%$ to $95 \%$ [18]. But the coverage of adequately iodized salt at household level is different from local to local due to different factors associated to it [11].

Moreover, a study done in Jigjiga showed that the rate of adequate iodized salt use at household level was 26.6\% [4]; household food cookers who had non corrugated iron sheet house, good knowledge were also predictors to adequately iodized salt. Similarly, a study done in Gondor town also reported that using packed salt, not exposing salt to sunlight, shorter storage of salt at household and good knowledge of participants about iodized salt were factors associated with availability of adequately iodized salt at household level [14]; the availability of adequately iodized salt ( $\geq 15 \mathrm{ppm}$ ) was $28.9 \%$.

Additionally, a study done in northwest Ethiopia reported that about $57.4 \%$ salt samples had iodine content in the range $15 \mathrm{ppm}$ to $59.42 \mathrm{ppm}$ [6]. This result indicates that salt stored in closed containers, salt samples stored in dry places and salt samples stored for less than two months were significantly associated with adequate iodine level.

According to a study done in Goba town, Ethiopia, only $30 \%$ of the households were covered by adequately iodized salt [1]; the associated factors that were found to be statistically significant with it were salt not exposing to sunlight, salt purchasing from supermarkets or big shops \& perceived cheap. In addition, a study done in north Ethiopia reported that the coverage of adequately iodized salt among the households was $17.5 \%$ [21], and family size, residence, the availability of iodized salt and affordability to iodized salt were strong predictors to proper iodized salt utilization.

Furthermore, a study done in Debre Tabor, Ethiopia revealed that the magnitude of poor knowledge and practice regarding iodized salt consumption was $53.8 \%$ and $55.6 \%$, respectively [20]. Studies conducted in Ethiopia also showed that occupational status, packaging, educational status, residence and knowledge were factors associated to the use of iodized salt utilization [20,24].

The Ethiopian rural communities have low levels of adequately iodized salt use compared to those who live in urban areas. Studies done in SNNPR [17] and in northwest Ethiopia [2] reported that urban households were used more adequately iodized salt $(\geq 15 \mathrm{ppm})$ compared to those households lived in rural areas.

However, little information is known regarding the availability of adequately iodized salt at the household level in the rural Horro woreda and factors associated to it. Therefore, this study was designed to assess the availability and utilization of adequately iodized salt at household level and its associated factors in rural communities of the study area.

\section{Materials and Methods}

\subsection{Description of the Study Area}

The study was conducted in Horro Woreda, Horro Guduru Wollega zone, Ethiopia. The study area Horro woread is located at about $314 \mathrm{~km}$ west of Addis Ababa. With geographical coordinates of $09^{\circ} 29^{\prime} \mathrm{N}$ and $37^{\circ} 26^{\prime} \mathrm{E}$, and at an altitude of approximately $2,296 \mathrm{~m}$. a. sl. Mixed croplivestock agriculture is the main stay in the area. The area has one long rainy season extending from March to mid October with annual rainfall ranging from $1000-2400 \mathrm{~mm}$. The monthly mean temperature varies from $14.9^{\circ} \mathrm{C}$ to $27^{\circ} \mathrm{C}$. The area is favorable for multi-disciplinary agricultural activities and livestock and fishery production.

\subsection{Study Design and Period}

A community based cross sectional study was done in Horro Woreda, Horro Guduru Wollega Zone, Ethiopia between February and March 2018.

\subsection{Source and Study Population}

All households in Horro Woreda, Horro Guduru Wollega Zone, Ethiopia were the source population while all households in Horro Woreda which were randomly selected from the four kebeles (Gitilo, Doyo Barso, Akeji Chabir and Sombo Dede) constituted the study population.

\subsection{Inclusion and Exclusion Criteria}

Participants in Horro Woreda who are the residents of the study area at least for six months were included in the study. 
Participants in Horro Woreda who are chronically sick at the time of study and not found at home during three visits were excluded from the study.

\subsection{Sample Size Determination}

The sample size was calculated using formula for a single population proportion by considering the following assumptions like 95\% CI $(Z=1.96)$, expected prevalence of Household inadequate iodized salt use $(\mathrm{p}=19 \%)$ and a margin of error 5\% [10]. The formula was yielded $n=236,10 \%$ of non-response rate and design effect of 1.5 to maximize sample size, lastly the required total sample size is 390 households.

\subsection{Sampling Procedures}

Multistage stages sampling methods were used to draw samples for the study. Firstly, from the 11 kebeles of the woreda, four rural kebeles (Gitilo, Doyo Barso, Akeji Chabir and Sombo Dede) were randomly selected. Then, all the households in the four kebeles were listed based on the data available in the woreda.

Next, the number of households in each kebele were determined by proportional allocation on the bases of total number of households in the respective kebeles. Finally, the households were randomly selected from each kebele.

\subsection{Data Collection Procedures}

The quantitative data were collected using a structured questionnaire adapted from different relevant studies. The questionnaire was first developed in English and then translated into Afan Oromo with some modification from the relevant sources. It was translated back to English by different language experts to check for consistency and then back to Afan Oromo to make interview with local respondents. The questionnaire was pre-tested on $5 \%$ of the sample in a kebele not included in the sample to check for its understandability and time required to complete the questionnaire before the actual data collection began. Based on feedback from the pretest, necessary corrections and editions were made in terminologies and formatting of the questionnaire.

To assess the use of iodized salt at the household level, interviewers were asked households to provide a teaspoon of table salt used for cooking. The salt samples about 20-50 gm were tested for iodine content using the iodine Rapid Test Kit.

After a training was given for two days, the data were collected by six diploma nurses and supervised by two public health professionals and the researcher. At the end of each day, the completeness of questionnaires were checked by the principal investigator.

\subsection{Variables of the Study}

The dependent variables were the use of iodized salt (inadequate use of iodized salt and adequate of use iodized salt) whereas independent variable were knowledge and practices of households about iodized salt, socio- demographic and economic characteristics of the respondents.

\subsection{Data Analysis}

Data were entered in to SPSS software v. 20.0. Before the analysis, data were checked for completeness and then cleaned. Descriptive statistics was run using tables, graphs, and percentages. Binary and multivariate logistic regression was used to identify factors associated to availability and utilization of adequately iodized salt. All independent variables that had a $p$-value $<0.25$ in the bivariate analysis were the candidates for multivariable logistic regression. A Pvalue less than 0.05 was considered statistically significant. The degree of association between dependent and independent variables was reported using adjusted odds ratio (AOR) and 95\% CI.

\subsection{Ethical Considerations}

Ethical clearance was obtained from Institutional Review Board (IRB) of the Wollega University, College of Health Sciences. A formal letter of permission was written to Regional Health Office, Horro Guduru Wollega Zonal Health Department, Horro Woreda Health Office, and to each selected kebele administration. After explaining the purpose of the study, verbal consent was obtained from each study participant. Participants were also be informed that participation is on voluntary basis and that they can withdraw at any time if they are not comfortable. Personal identifiers were not included in the questionnaires to ensure participants' confidentiality. Nutrition education on the importance, source of iodized salt and practice of it at household level were given by the data collectors for households with low iodized salt during the survey.

\section{Results}

\subsection{Socio-demographic Characteristics}

A total of 390 households were included in this study with a response rate of $100 \%$. Of 390 rural participants, 380 (97.43\%) were Oromo by ethnicity and the left $10 \%(2.56 \%)$ participants were Amhra. Three hundred twenty (82\%) and seventy (18\%) participants in the study were Protestant and Orthodox in religion, respectively. This study also reported that about $345(88.46 \%)$ participants were married, 30 $(7.69 \%)$ were single and $15(3.85 \%)$ were divorced. Regarding the educational status, about $180 \quad(46.2 \%)$ participants had attended formal education while 210 $(53.8 \%)$ had not.

Table 1. Socio-demographic and economic characteristics of the study participants, Horro Woreda, Oromia region, Ethiopia, 2018.

\begin{tabular}{lll}
\hline Variables & Frequency & Percentage (\%) \\
\hline Age (year) & & \\
$18-31$ & 68 & 17.43 \\
$32-45$ & 165 & 42.3 \\
$>45$ & 157 & 40.25 \\
\hline
\end{tabular}




\begin{tabular}{lll}
\hline Variables & Frequency & Percentage (\%) \\
\hline Marital status & & \\
Single & 30 & 7.69 \\
Married & 345 & 88.46 \\
Divorced & 15 & 3.846 \\
Education status & & \\
Attend formal education & 180 & 46.2 \\
Not attend formal education & 210 & 53.8 \\
Income & & \\
$>500$ ETB & 146 & 37.43 \\
$<500$ ETB & 244 & 62.56 \\
Occupational status & & \\
Civil servant (salary) & 68 & 17.43 \\
Daily labor & 42 & 10.769 \\
Farmer & 240 & 61.53 \\
Merchant & 40 & 10.25 \\
\hline ETB=Ethiopian Birr. & &
\end{tabular}

\subsection{Availability and Adequacy of Iodine in Household Salts}

This study showed that $210(53.8 \%)$ participants used iodized salts at their home. However, out of 390 households who used iodized salts, only $92(23.6 \%)$ of households used adequately iodized salt ( $\geq 15$ ppm) while 220 (56.4\%) households used iodized salts $(<15 \mathrm{ppm})$ during the survey. No iodine was found in salts used by $78(20 \%)$ households (Figure 1).

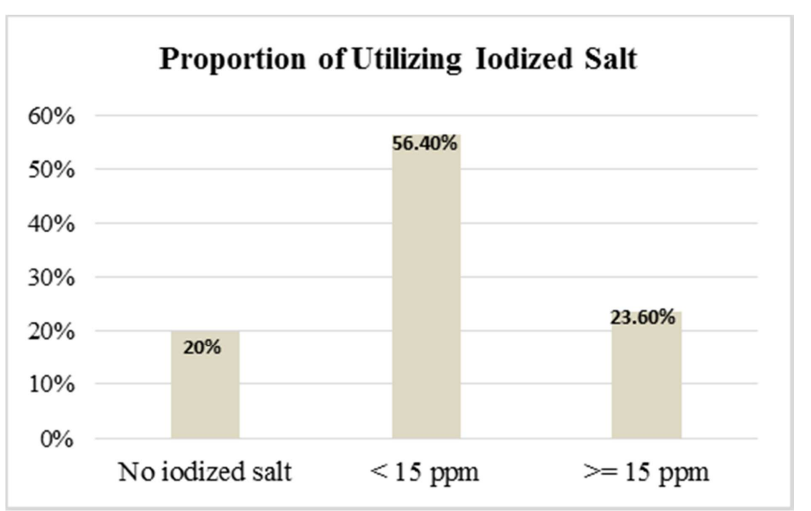

Figure 1. Proportion of utilizing iodized salt, Horro Woreda, Oromia region, Ethiopia, 2018.

\subsection{Knowledge of Participants Regarding the Importance of Iodized Salt}

This study reported that one hundred forty three (36.7\%) participants said iodized salt prevents from IDDs and knew about iodine deficiency disorders and their effects on human beings. When asked if they have ever heard about iodized salt, $150(38.46 \%)$ respondents said that they have heard about iodized salt. About 150 (38.46\%) participants have got the information from mass media, health extension workers. The remaining $240(61.5 \%)$ participants had not heard about iodized salt (Table 2).

Table 2. Knowledge of participants regarding iodized salt, Horro Woreda, Oromia, Ethiopia, 2018

\begin{tabular}{lcl}
\hline Variables & Frequency & Percentage (\%) \\
\hline $\begin{array}{l}\text { Heard about iodized salt } \\
\text { Yes }\end{array}$ & 150 & 38.46 \\
\hline
\end{tabular}

\begin{tabular}{lll}
\hline Variables & Frequency & Percentage (\%) \\
\hline No & 240 & 61.5 \\
Food Sources of iodine & & \\
Meat & 31 & 7.95 \\
Bread & 43 & 11 \\
Fish, dairy products, eggs & 67 & 17.2 \\
Fruits, vegetables & 18 & 4.6 \\
I don't know & 231 & 59.2 \\
Importance of using iodized salt & & \\
It prevents from IDDs & 112 & 28.7 \\
I don't know & 278 & 71.3 \\
Knew effects of iodine deficiency & & \\
Yes & 143 & 36.7 \\
No & 247 & 63.3 \\
Knowledge & & \\
Good & 141 & 36.2 \\
Poor & 249 & 63.8 \\
\hline
\end{tabular}

\subsection{Utilization Pattern/Practices/of Iodized Salt}

About 180 (46.2\%) participants did not have iodized salt while $210(53.8 \%)$ participants had adequately iodized salt during the survey. The majority $280(71.8 \%)$ of participants have got iodized salts from nearby shops.

Two hundred one (51.5\%) households used non-packed salt while the remaining $189(48.5 \%)$ households used packed salt. In addition, 197 (50.5\%) of participants used cover for their salt containers whereas 193 (49.5\%) participants did not. Majority $256(65.5 \%)$ of participants, stored salt in a fire area. Moreover, about 246 (63.1\%) participants stored salt for less than two months while 144 (36.9\%) used for more than two months (Table 3).

Table 3. Utilization pattern/practices/ of iodized salt, Horro Woreda, Oromia, Ethiopia, 2018.

\begin{tabular}{|c|c|c|}
\hline Variables & Frequency & Percentage (\%) \\
\hline \multicolumn{3}{|l|}{ Access to iodized salt } \\
\hline Yes & 210 & 53.8 \\
\hline No & 180 & 46.2 \\
\hline \multicolumn{3}{|l|}{ Source of iodized salt } \\
\hline Market & 280 & 71.8 \\
\hline Nearby shops & 65 & 16.7 \\
\hline Pharmacy & 45 & 15.54 \\
\hline \multicolumn{3}{|l|}{ Salt container } \\
\hline With cover & 197 & 50.5 \\
\hline Without cover & 193 & 49.5 \\
\hline \multicolumn{3}{|l|}{ Salt storage place } \\
\hline Dry and cool place & 80 & 20.5 \\
\hline Moisture area & 54 & 13.85 \\
\hline Fire area & 256 & 65.5 \\
\hline \multicolumn{3}{|l|}{ Washing salt before use } \\
\hline Yes & 48 & 12.3 \\
\hline No & 342 & 87.7 \\
\hline \multicolumn{3}{|l|}{ Duration of salt storage at $\mathrm{HH}$ level } \\
\hline$<2$ months & 246 & 63.1 \\
\hline$\geq 2$ months & 144 & 36.9 \\
\hline \multicolumn{3}{|l|}{ Type of salt used } \\
\hline Packed & 201 & 51.5 \\
\hline Not packed & 189 & 48.5 \\
\hline Time salt was added during cooking & & \\
\hline $\begin{array}{l}\text { Late at the end of cooking or after } \\
\text { cooking }\end{array}$ & 108 & 27.69 \\
\hline $\begin{array}{l}\text { Early or at the middle of cooking } \\
\text { Iodized salt utilization practices }\end{array}$ & 282 & 72.31 \\
\hline Good & 156 & 40 \\
\hline
\end{tabular}




\begin{tabular}{lll}
\hline Variables & Frequency & Percentage (\%) \\
\hline Poor & 234 & 60 \\
\hline
\end{tabular}

\subsection{Factors Associated with Availability of Adequately Iodized Salt}

The bivariate analysis of this study showed access to information, wealth index, sources of iodine, knowledge about the benefit of iodized salt, salt, using cover for salt container, type of salt and salt storage place were significantly associated with availability to adequately iodized salt.

However, in the multivariate analysis, only access to information, wealth index, salt storage place and knowledge about the benefit of iodized salt were significantly associated with availability to adequately iodized salt.

Table 4. Factors associated with availability of adequately iodized salt, Horro Woreda Horro Guduru Wollega Zone, Oromia, Ethiopia, 2018 (n=390).

\begin{tabular}{|c|c|c|c|c|}
\hline \multirow{2}{*}{ Variables } & \multicolumn{2}{|c|}{ Frequency } & \multirow[t]{2}{*}{ COR $(95 \% \mathrm{CI})$} & \multirow[t]{2}{*}{ AOR (95\% CI) } \\
\hline & $\geq 15 p p m$ & $<15 \mathrm{ppm}$ & & \\
\hline \multicolumn{5}{|l|}{ Access to information about iodized salt } \\
\hline Yes & 135 & 88 & $3.1(1.52,6.32)^{*}$ & $2.5(1.1,5.55)^{* *}$ \\
\hline No & 73 & 94 & 1 & 1 \\
\hline \multicolumn{5}{|l|}{ Source of iodized salt } \\
\hline Market & 129 & 54 & 1 & 1 \\
\hline Nearby shops & 60 & 72 & $2.63(1.65,4.2)^{*}$ & $.746(.31,1.797)$ \\
\hline Pharmacy & 35 & 40 & $2.44(1.52,3.93)^{*}$ & $1.16(.65,2.08)$ \\
\hline \multicolumn{5}{|l|}{ Wealth index } \\
\hline High & 78 & 42 & $5.69(3.3,9.94)^{*}$ & $4.7(2.5,8.83)^{* *}$ \\
\hline Medium & 60 & 63 & $1.696(.924,3.11)^{*}$ & $1.399(.71,2.757)$ \\
\hline Low & 34 & 113 & 1 & 1 \\
\hline \multicolumn{5}{|l|}{ Time salt was added during food cooking } \\
\hline Early or at the middle of cooking & 141 & 28 & 1 & \\
\hline Late at the middle of cooking or after cooking & 108 & 113 & $1.88(.923,3.2)$ & - \\
\hline \multicolumn{5}{|l|}{ Knowledge about benefit of iodized salt } \\
\hline Yes & 201 & 65 & $1.96(1.6,3.9)^{*}$ & $1.4(1.6,2.08)^{* *}$ \\
\hline No & 81 & 43 & 1 & 1 \\
\hline \multicolumn{5}{|l|}{ Using cover for salt container } \\
\hline Yes & 38 & 122 & 1 & 1 \\
\hline No & 63 & 167 & $1.887(.92,3.86)^{*}$ & $1.13(.456,2.78)$ \\
\hline \multicolumn{5}{|l|}{ Educational Status } \\
\hline Attended formal education & 96 & 75 & $1.72(0.26,2.9)$ & - \\
\hline Not attended formal education & 85 & 134 & 1 & \\
\hline \multicolumn{5}{|l|}{ Salt storage place } \\
\hline Dry and cool place & 90 & 87 & $6.5(1.72,24.6)^{*}$ & $4.2(2.33,13.54)^{* *}$ \\
\hline Moisture area & 22 & 18 & $1.22(.69,2.15)^{*}$ & $1.44(.62,3.35)$ \\
\hline Fire area & 120 & 53 & 1 & 1 \\
\hline \multicolumn{5}{|l|}{ Type of salt } \\
\hline Packed & 98 & 95 & $2.44(1.52,3.93)^{*}$ & $1.16(.65,2.08)$ \\
\hline Not packed & 32 & 165 & 1 & 1 \\
\hline
\end{tabular}

* P- value $<0.25$ in the bivariate analysis, ${ }^{* *} \mathrm{P}$-value $<0.05$ in the multivariate analysis, $1=$ References.

\section{Discussion}

At household level, the recommended iodine concentration in salt should be 20-40 ppm to provide iodine [19]. However, iodine level in the salt examined in this study was clearly not iodized in accordance with this recommendation. The iodine concentration of salt varied from $0-156 \mathrm{ppm}$, which indicates the need to further improve the quality of iodized salt at the point of production. This might be due to traditional salt production process and manual iodization, manual mixing does not achieve the required uniformity throughout the salt pile. In addition to this raw salt with high level of impurities, high moisture, large crystal agglomerates may not be able to maintain the quantity and homogeneity of iodine [9]. According to this study, iodized salt was found in 210 households (53.8\%). However, adequately iodized salt $(\geq 15$ ppm) was found in 92 (23.6\%) households only. This iodized salt coverage result was less compared to studies done in
Mecha district, 25.7\% [24], Jigjiga, 26.6\%) [4], Gondor, 28.9\% [14] and in Sothern Nation, Nationalities and People Representative (SNNPR), $65.5 \%$ in urban \& $45.2 \%$ in rural [17] and at national, 26\%) [13]. This differences could be due to the present survey was done in rural communities where information about iodized salt is low.

On the other hand, this finding of this study is higher compared to a study done in north Ethiopia, 17.5\% [21], and a national survey conducted in Ethiopia, 15.4\%. [10]. This difference might be due to the number of reasons such as study area differences, sample size, current house to house educational strategy through health extension workers organized both in the urban and rural communities.

According to this study, households who had information were 2.5 times more used adequately iodized salt than those who had no information $(\mathrm{AOR}(95 \% \mathrm{CI})=2.5(1.1,6.55))$. This result is similar with a study done in SNNPR [17], which reported that those households who had access to 
information were 3.99 times more likely to use adequately iodized salt than those who had no access to information $(\operatorname{AOR}(95 \% \mathrm{CI})=3.99(2.54,6.27))$. This finding is consistent with the study done in Northwest Ethiopia [20], which showed that participants who had information from school, AOR $(95 \% \mathrm{CI})=0.42(0.242,0.711)$ and television, AOR $(95 \% \mathrm{CI})=0.463(0.276,0.777)$ were less likely to practice wrongly in iodized salt consumption compared to those who had no information.

Studies done in Tigray, Ethiopia [15] and Ghana [3] also showed that media's role, where access to formal education opportunities were not available, access to information through media served as an important instrument to educate the public and increase the community's knowledge on the nutritional value of consuming adequately iodized salt. This better availability and utilization of iodized salt in the study area might be due to access to information and proximity to nearby shops to buy iodized salt for consumption than those who had no information.

Regarding participants' knowledge, this study reported that households who had knowledge about the benefit of iodized salt were 1.4 times more likely to use adequately iodized salt than those who did not know (AOR $(95 \% \mathrm{CI})=1.4$ (1.6, 2.08)). This result is supported by a study done in SNNPR [17] which showed that those households who did know the benefit of iodized salt were 4.466 times more likely to use adequately iodized salt than those who did not know (AOR $(95 \% \mathrm{CI})=4.66(3.01,7.22))$. A study done in northern Ethiopia [15] also reported that those household who did know the benefit of iodized salt were 2.11 times more likely to use adequately iodized salt than their counterparts (AOR $(95 \% \mathrm{CI})=2.11(1.37,3.25))$. In addition, a study done in Northwest Ethiopia showed that those participants who were unable to read and write, AOR $(95 \% \mathrm{CI})=2.18(1.043$, 4.566)) were two times more likely to have poor practice compared to those having university and above educational status [20]. Similarly, a study done in Gondar town, Ethiopia [14] reported that knowledge of participants about the iodized salt was significantly associated with availability of adequately iodized salt (AOR $(95 \% \mathrm{CI})=1.94(1.23,3.05)$.

Furthermore, a study conducted in Ghana showed the result of increased knowledge regarding the importance of using iodized salt and the effects of its deficiency in the diet of an individual; there has also been an increase in the consumption rate of iodized salt [7]. Another a study done in Mecha district, Ethiopia [24] also reported that participants who had good knowledge were three times more likely to utilize adequately iodized salt compared those who had poor knowledge $($ AOR $(95 \% \mathrm{CI})=3.8(2.1,6.8$. $)$.

Concerning wealth index, the current study showed that households lived in high wealth index were 4.7 times more likely to get adequately iodized salt than those households in medium and low wealth index $(\mathrm{AOR}(95 \% \mathrm{CI})=4.7(2.5$, 8.88). In addition, a study done in SNNPR [17] also reported that having monthly income $>500$ ETB was significantly associated with availability of adequately iodized salt (AOR $(95 \% \mathrm{CI}=7.16(4.55,11.29))$.
Another study done in Ethiopia among school children [2] also showed that medium household wealth status were 1.78 times more likely to get adequately iodized salt compared to those household in low wealth status (AOR 95\% CI=1.78 $(1.18,2.92))$. Similar study conducted in Ghana revealed that compared to the highest wealth index households, those who in lower levels of wealth index were more likely to use noniodized salt [3]. This could be due to the fact that those who have high income may buy iodized salt easily and provide it for household family compared to those households who live in low income.

According to this study households who store their salt at dry and cool place were 4.2 times likely to get adequately iodized salt than those who store at moisture and fire area (AOR $(95 \% \mathrm{CI}=4.2(2.33,13.54)$ ). A study done in Jigjiga [4] reported results that food cookers who were using dry place to store their salt were found to use adequate iodized salt significantly more than those who had moist place and fire area $(\mathrm{AOR}, 95 \% \mathrm{CI}=5.15(1.32,20.06))$.

Furthermore, a study in Dera District, North Shewa zone, Oromia region, Ethiopia [6] showed that salt samples stored in dry places were 1.5 times more likely to retain iodine compared to samples stored near to heat/fire or in a moist area (AOR $(95 \% \mathrm{CI}=1.5(1.03,2.14)$. This could be due to the fact that salt stored in humid condition and stay for longer period attracts moisture and becomes wet and may loss edible iodine. At hot condition, salt can release surface moisture, and this may cause an iodine loss by its volatility if the container of edible iodine salt is not packed.

\section{Conclusions}

This study concluded that the proportion of households covered by adequately iodized salt in rural communities of Horro Woreda, Oromia region, Ethiopia was low (23.6\%) compared to the internationally recommended value to control iodine deficiency disorder (IDD) $(>=90 \%)$. In addition, this study also revealed that participants' had inadequate knowledge and practice regarding adequately iodized salt was $63.8 \%$ and $60 \%$, respectively. This indicates that the survey was done in rural communities where access to information is low. Efforts need to be intensified through better educational programmes on the benefits, its practice and increased use of adequately iodized salt at household level in the study area. Moreover, the findings of this study suggested that access to information, wealth status, knowledge regarding the benefits of iodized salt and its storage place were factors significantly associated with coverage of adequately iodized salt at household level. Therefore, nutrition education intervention through behavioral change communication (BCC) towards adequately iodized salt utilization and its practice should be strengthen by health extension workers and nutritionists to increase its coverage and to eliminate iodine deficiency disorders (IDD). Furthermore, researches are recommended to look at the possible factors to use adequately iodized salt at manufacturers, whole, sellers and retailers to prevent the 
production and distribution of under iodized salt in the market. The findings are of interest to local public sectors and non-governmental organizations for informed decisions in addition to provide baseline information and updated evidence for future researches in the study area.

\section{Acknowledgements}

The author acknowledge the Department of Food Science and Nutrition, Wollega University for financial support. The author also declared that there is no conflict of interests.

\section{References}

[1] Abdurrahman, K., Fentie, A., and Dereje, B. (2015). Coverage of Iodized Salt and Associated Factors at Household Level in Goba Town, Bale Zone, South East Ethiopia. Science Journal of Public Health. Vol. 4 (4): pp 346-351.

[2] Abebe, Z., Gebeye, E., and Tariku, A. (2017). Poor dietary diversity, wealth status and use of un-iodized salt are associated with goiter among school children: a crosssectional study in Ethiopia. Journal of BMC Public Health 17: 44.

[3] Ahiadeke, C., Charles, A., Richmond, A., and Adjoa, A. (2012). Factors influencing the use of adequately iodated salt in Ghana. African Journal of Food Science v. 6 (3): 58-64.

[4] Ahmed, T., Berhanu, S., and Haji, K. (2016). Use of Iodized Salt at Household Level in Jigjiga Town, Eastern Ethiopia. Asian Journal of Agriculture \& Life Sciences. Vol. 1 (2): 1824.

[5] Guidelines of the American Thyroid Association for the Diagnosis and Management of Thyroid Disease during Pregnancy and the Postpartum (2017). Thyroid 27 (3): 315-389.

[6] Anteneh, A., Engidayehi, M., and Abeje, D. (2017). Iodine content of dietary salt at household level and associated factors using Iodometric titration methods in Dera District, Northwest Ethiopia. BMC Nutrition 3: 83.

[7] Buxton, C., and Baguune, B. (2012). Knowledge and practices of people in Bia District, Ghana, with regard to iodine deficiency disorders and intake of iodized salt, Archives of Public Health, vol. 70 (5): 70-75.

[8] CDC, (2015). Centre for Disease Control and Prevention International; Micronutrient Malnutrition Prevention and Control.

[9] Chuko, T., Bagrianky, J., and Brown, T. (2015). Ethiopia's long road to USI. IDD Newsletter. 43 (2).

[10] CSA and ICF, (2012). Ethiopia Demographic and Health Survey 2011, Central Statistical Agency and ICF International, Calverton, Md, USA.

[11] EPHI, (2014). National salt iodization coverage towards prevention of iodine deficiency disorders in Ethiopia.
[12] Ethiopian Council of Ministers, (2014). Salt Iodization Council of Ministers Regulation. Addis Ababa, Ethiopia.

[13] EPHI, (2016). Ethiopian Public Health Institute. National Micronutrient Survey Report Addis Ababa: Federal Ministry of Health, Report No. 10.

[14] Gebremariam, G., Yesuf, E., and Koye, D. (2013). Availability of Adequately Iodized Salt at Household Level and Associated Factors in Gondar Town, Northwest Ethiopia Hindawi Publishing Corporation, ISRN Public Health, Volume 2013.

[15] Gidey, B., Alemu, K., Atnafu, A., Kifle, M., and Tefera, Y. (2015). Availability of Adequate Iodized Salt at Household Level and Associated Factors in Rural Communities of Laelay Maychew District, Northern Ethiopia: J Nutr Health Sci 2 (1): 103.

[16] Hussein I and Assey V (2012). Elimination of Iodine Deficiency through Salt Iodization in Ethiopia, International council for the control of iodine deficiency disorders (ICCIDD), Addis Ababa, Ethiopia.

[17] Masresha, T, Dejene, H and Menen, Z. (2016). Availability and Utilization of Adequately Iodized Salt by Urban and Rural Households and Associated Factors in Southern Ethiopia, Sidama Zone, Bensa Woreda: A Comparative Cross-sectional Study. International Journal of Food Science and Nutrition Engineering Vol 6 (3): 62-71.

[18] NNP, (2015). National Nutrition Policy; Government of the Federal Democratic Republic of Ethiopia June 2013-June 2015.

[19] WHO, (2017). World Health Organization; Micronutrients.

[20] Tadesse, W., Tadesse, A., and Girma, N. (2019). Knowledge and Practice on Iodized Salt Consumption and Associated Factors at a Household level at Debre Tabor Town, Northwest Ethiopia”. EC Nutrition 14: 01-12.

[21] Desta, A., Kulkarni, U., Abraha, K., Worku, S., and Sahle, B. (2019). Iodine level concentration, coverage of adequately iodized salt consumption and factors affecting proper iodized salt utilization among households in North Ethiopia: a community based cross sectional study, BMC Nutrition 5: 28 .

[22] Zimmermann, M. (2012). "The effects of iodine deficiency in pregnancy and infancy,"Paediatric and Perinatal Epidemiology, vol. 26, supplement 1, pp. 108-117.

[23] Rajwinder, H., Mieke, F., Folake, S., Afework, M., Judith, K., and Ans, E. (2017). Are Low Intakes and Deficiencies in Iron, Vitamin A, Zinc, and Iodine of Public Health Concern in Ethiopian, Kenyan, Nigerian, and South African Children and Adolescents? Food and Nutrition Bulletin Vol. 38 (3) 405-427.

[24] Walleligne, BT., and Amare, LM. (2019). Knowledge and Utilization of Iodized Salt and Its Associated Factors at Household Level in Mecha District, Northwest Ethiopia. Journal of Nutrition and Metabolism Volume 2019, Article ID 9763830,8 pages. 